\title{
Tamsulosin and Tadalafil in Relieving Benign Prostatic Hyperplasia Related Symptoms- A Comparative Study
}

\author{
A. Nischal Prasad ${ }^{\circ 1}$, Nand Kumar B. Madhekar ${ }^{\circ} 2$ \\ ${ }^{1}$ Associate Professor, Department of Urology, Sapthagiri Institute of Medical Sciences and Research Center, Bangalore, Karnataka, India, ${ }^{2}$ Assistant Professor, \\ Department of Urology, Sapthagiri Institute of Medical Sciences and Research Center, Bangalore, Karnataka, India.
}

\section{Abstract}

Background: Benign prostatic hyperplasia (BPH) is the most common neoplastic condition afflicting men and constitutes a major factor impacting the health of the male. The present study compared tamsulosin and tadalafil in relieving benign prostatic hyperplasia related symptoms in patients. Subjects and Methods: The present study was conducted at NRI Medical College \& Hospital, Chinakakani, Mangalagiri Mandal, Andhra Pradesh from April 2007 to March 2008 on 82 men of $>45$ years of age with LUTS secondary to benign prostatic hyperplasia (BPH) with an IPSS $>8$. All patients were divided into 2 weeks. In group I, Tadalafil $10 \mathrm{mg}$ once daily with an intervening 4-week period of placebo (P4) wash out followed by Tamsulosin $0.4 \mathrm{mg}$ once daily were administered for a period of 6 weeks and in group II, reverse of it was administered. IPSS scores, Uroflowmetry parameters and International Index of Erectile Function-5 scores were recorded in both groups. Results: Age group 45- 55 years had $12,55-65$ years had 28 and $>65$ years had 42 patients. The difference was significant $(\mathrm{P}<0.05)$. Comorbidities such as diabetes mellitus was present in 4 in group I and 5 in group II, bronchial asthma 5 in group I and 3 in group II, Hypertension was present in 7 in group I and 9 in group II and both hypertension and diabetes mellitus was present in 10 in group I and 12 in group II. The difference was significant $(\mathrm{P}<0.05)$. Mean IPSS total score, IPSS voiding score, IPSS storage score and IPSS QOL score at baseline, 2 weeks and 8 weeks in group I and group II was non- significant $(\mathrm{P}>0.05)$. Conclusion: Authors found that both Tadalafil and Tamsulosin improved LUTS and benign prostrate hyperplasia symptoms.

Keywords: Benign prostatic hyperplasia, Tadalafil, Tamsulosin

Corresponding Author: Nand Kumar B. Madhekar, Assistant Professor, Department of Urology, Sapthagiri Institute of Medical Sciences and Research Center, Bangalore, Karnataka, India.

E-mail: nkmadhekar2013@gmail.com

Received: 11 January 2020

Revised: 17 February 2020

Accepted: 02 March 2020

Published: 26 May 2020

\section{Introduction}

Benign prostatic hyperplasia (BPH) is the most common neoplastic condition afflicting men and constitutes a major factor impacting the health of the male. BPH and sexual dysfunction is often co-existent in ageing males. Population based and longitudinal studies have shown a strong correlation between erectile dysfunction (ED) and lower urinary tract symptoms (LUTS) secondary to BPH. Sexual disorders and their related bother has been found to correlate strongly with age and the severity of LUTS, independent of the other co-morbidities. Although a causal link between LUTS and ED is not well established, four main pathophysiological mechanisms, with varying degrees of overlap currently support this relationship. ${ }^{[1]}$

This pathologic change is important because of the intimate anatomic relationship between the prostate and the bladder neck. The association of BPH with aging has been demonstrated repeatedly in autopsy studies using calculated or actual weight, prostate volume, or histologic criteria. ${ }^{[2]}$

Environmental and hereditary factors also influence the development of clinical BPH. The incidence of BPH is reported to be much lower in Chinese and Japanese men living in Asia than in white populations. ${ }^{[3]}$ Data on the racial background of patients subjected to prostatectomy in Hawaii also provide evidence suggesting a relatively lower incidence of BPH in Chinese and Japanese men than in white men. These and other studies support a genetic factor in the development of these lesions. ${ }^{[4]}$ Clinical evaluation to assess the presence and degree of voiding dysfunction and/or the role of BPH in its presence has an increasingly broad spectrum of treatment goals. These include providing information on a range of epidemiologic studies, selecting patients for drug or interventional studies, and providing information and advice to 
individual patients. ${ }^{[5]}$ The present study compared tamsulosin and tadalafil in relieving benign prostatic hyperplasia related symptoms in patients.

\section{Subjects and Methods}

The present study was conducted at NRI Medical College \& Hospital, Chinakakani, Mangalagiri Mandal, Andhra Pradesh from April 2007 to March 2008 on 82 men of $>45$ years of age with LUTS secondary to benign prostatic hyperplasia (BPH) with an IPSS $>8$. All were informed regarding the study and written consent was obtained. Ethical clearance was obtained prior to the study.

Data such as name, age etc. was recorded. A through clinical examination was performed in all patients. All patients were divided into 2 weeks. In group I, Tadalafil $10 \mathrm{mg}$ once daily with an intervening 4-week period of placebo (P4) wash out followed by Tamsulosin $0.4 \mathrm{mg}$ once daily were administered for a period of 6 weeks and in group II, reverse of it was administered. IPSS scores, Uroflowmetry parameters and International Index of Erectile Function-5 scores were recorded in both groups. Results thus obtained were subjected to statistical analysis. $\mathrm{P}$ value less than 0.05 was considered significant.

\section{Results}

\begin{tabular}{|lll|}
\hline \multicolumn{2}{|l|}{ Table 1: Distribution of patients } & \\
\hline Age group (Years) & Number & P value \\
\hline $45-55$ & 12 & 0.01 \\
\hline $55-65$ & 28 & \\
$>65$ & 42 & \\
\hline
\end{tabular}

[Table 1] shows that age group 45- 55 years had 12, 55-65 years had 28 and $>65$ years had 42 patients. The difference was significant $(\mathrm{P}<0.05)$.

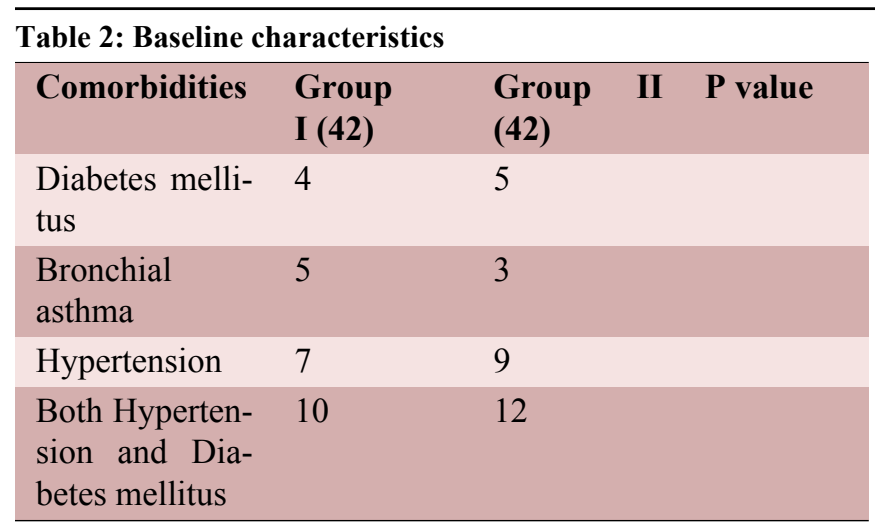

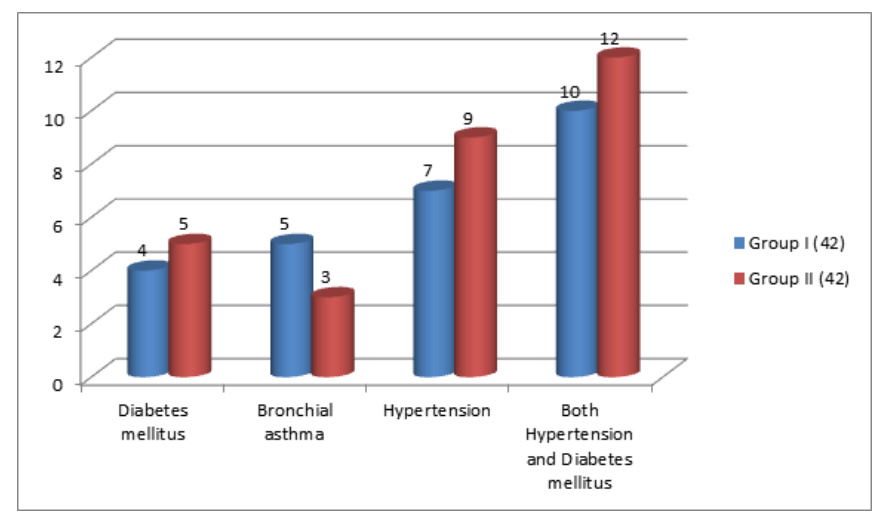

Figure 1: Baseline characteristics

\begin{tabular}{|c|c|c|c|c|}
\hline Variables & Duration & Group I & $\begin{array}{l}\text { Group } \\
\text { II }\end{array}$ & P value \\
\hline \multirow[t]{3}{*}{ IPSS } & Baseline & 17.6 & 16.9 & 0.14 \\
\hline & 2 weeks & 16.4 & 16.5 & \\
\hline & 8 weeks & 9.2 & 9.5 & \\
\hline \multirow[t]{3}{*}{ IPSS } & Baseline & 11.4 & 10.6 & 0.01 \\
\hline & 2 weeks & 10.2 & 10.1 & \\
\hline & 8 weeks & 5.3 & 6.4 & \\
\hline \multirow[t]{3}{*}{ IPSS } & Baseline & 5.2 & 5.1 & 0.04 \\
\hline & 2 weeks & 4.7 & 4.5 & \\
\hline & 8 weeks & 3.1 & 3.0 & \\
\hline \multirow[t]{3}{*}{ IPSS } & Baseline & 3.0 & 4.6 & 0.94 \\
\hline & 2 weeks & 2.8 & 4.1 & \\
\hline & 8 weeks & 2.6 & 2.3 & \\
\hline
\end{tabular}

[Table 2, Figure 1] shows that comorbidities such as diabetes mellitus was present in 4 in group I and 5 in group II, bronchial asthma 5 in group I and 3 in group II, Hypertension was present in 7 in group I and 9 in group II and both hypertension and diabetes mellitus was present in 10 in group I and 12 in group II. The difference was significant $(\mathrm{P}<0.05)$.

[Table 3, Figure 2] shows that mean IPSS total score at baseline in group I was 17.6 and 16.9 in group II, at 2 weeks was 16.4 in group I and 16.5 in group II and at 8 weeks was 9.2 in group I and 9.5 in group II. IPSS voiding score at baseline in group I was 11.4 and 10.6 in group II, at 2 weeks was 10.2 in group I and 10.1 in group II and at 8 weeks was 5.3 in group I and 6.4 in group II. IPSS storage score at baseline in group I was 5.2 and 5.1 in group II, at 2 weeks was 4.7 in group I and 4.5 in group II and at 8 weeks was 3.1 in group I and 3.0 in group II. IPSS QOL score at baseline in group I was 3.0 and 4.6 in group II, at 2 weeks was 2.8 in group I and 4.1 in group 


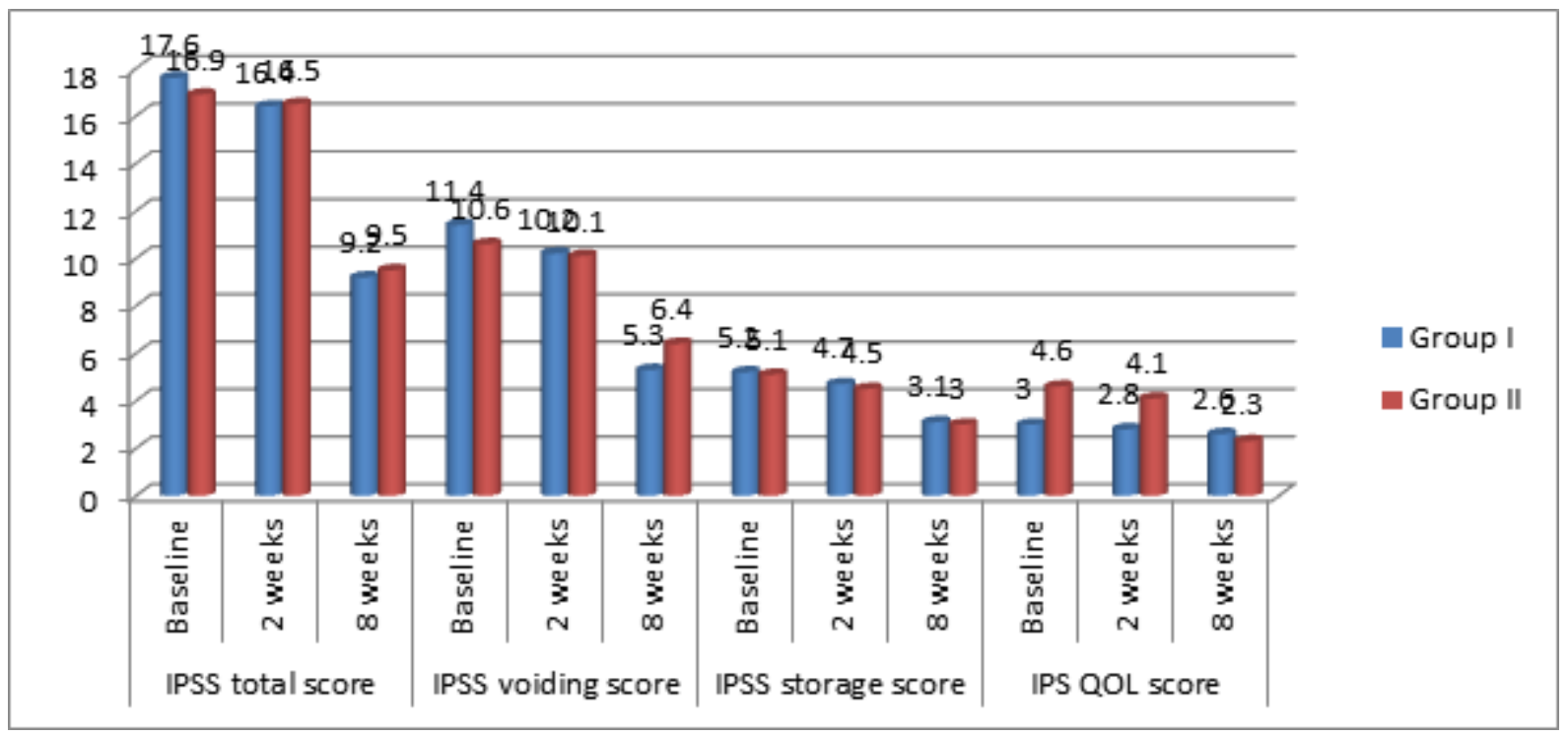

Figure 2: Effect of the treatment in both groups

II and at 8 weeks was 2.6 in group I and 2.3 in group II. The difference was non- significant $(\mathrm{P}>0.05)$.

\section{Discussion}

Benign prostatic hyperplasia (BPH) is a histological diagnosis associated with unregulated proliferation of connective tissue, smooth muscle and glandular epithelium within the prostatic transition zone. ${ }^{[6]}$ Prostate tissue is composed of two basic elements: A glandular element composed of secretory ducts and acini; and a stromal element composed primarily of collagen and smooth muscle. ${ }^{[7]} \mathrm{In} \mathrm{BPH}$, cellular proliferation leads to increased prostate volume and increased stromal smooth muscle tone. McNeal describes two phases of BPH progression. The first phase consists of an increase in BPH nodules in the periurethral zone and the second a significant increase in size of glandular nodules. ${ }^{[8]} \mathrm{BPH}$ may cause physical compression of the urethra and result in anatomic bladder outlet obstruction (BOO) through two distinct mechanisms: First, an increase in prostate volume, termed the static component; second, an increase in stromal smooth muscle tone, termed the dynamic component. BOO, in turn, may present clinically as lower urinary tract symptoms (LUTS), urinary tract infections, acute urinary retention (AUR), renal failure hematuria, and bladder calculi. ${ }^{[9]}$ The present study compared tamsulosin and tadalafil in relieving benign prostatic hyperplasia related symptoms in patients.

In present study, age group 45- 55 years had 12, 55-65 years had 28 and $>65$ years had 42 patients. Comorbidities such as diabetes mellitus was present in 4 in group I and 5 in group II, bronchial asthma 5 in group I and 3 in group II, Hypertension was present in 7 in group I and 9 in group II and both hypertension and diabetes mellitus was present in 10 in group I and 12 in group II.

Pattanaik et al, ${ }^{[10]}$ found that Tadalafil and tamsulosin significantly improved the total IPSS score and quality of life as compared to the baseline. However, there were no significant differences between the two drugs with respect to extent of observed effect and which drug was prescribed 1 st in the sequence respectively. Significant period effect was observed i.e., the symptoms did not return to the baseline before the second treatment. Half of the nonresponders to either of the drugs responded when the drug was changed to the other. Tadalafil showed better improvement in EF score as compared to Tamsulosin.

We found that mean IPSS total score, IPSS voiding score, IPSS storage score and IPSS QOL score at baseline, 2 weeks and 8 weeks in group I and group II was non- significant ( $\mathrm{P}>0.05)$. LUTS describes a distinct phenotype of a group of disorders affecting the prostate and bladder that share a common clinical manifestation. In recent years, LUTS has become the preferred term for studying urinary symptoms in male populations because it allows for a broad, epidemiological description of urinary symptoms without identification of organ- or disease- specific etiologies. ${ }^{[11]}$ The most commonly used measures of LUTS in epidemiologic studies are the American Urological Association Symptom Index (the AUA-SI) and its internationally validated counterpart, the International Prostate Symptom Score (I-PSS). The AUA-SI and I-PSS are robust and reliable metrics for measuring male LUTS. 
The AUA, European Association of Urology and the World Health Organization International Consultation on Urologic Disease recommend the routine use of the I-PSS in the clinical evaluation of patients with suspected BPH and BOO. ${ }^{[12]}$

\section{Conclusion}

Authors found that both Both Tadalafil and Tamsulosin improved LUTS and benign prostrate hyperplasia symptoms.

\section{References}

1. Mcneal J. Pathology of benign prostatic hyperplasia. Insight into etiology. Urol Clin North Am. 1990;17:477-86.

2. Jung JH, Jae SU, Kam SC, Hyun JS. Correlation between lower urinary tract symptoms (LUTS) and sexual function in benign prostatic hyperplasia: Impact of treatment of LUTS on sexual function. J Sex Med. 2009;6:2299-304.

3. McVary KT, Roehrborn CG, Avins AL, Barry MJ, Bruskewitz $\mathrm{RC}$, Donnell RF, et al. Update on AUA Guideline on the Management of Benign Prostatic Hyperplasia. J Urol. 2011;185(5):1793-1803. Available from: https://dx.doi.org/10. 1016/j.juro.2011.01.074. doi:10.1016/j.juro.2011.01.074.

4. Stroup SP, Palazzi-Churas K, Kopp RP, Parsons JK. Trends in adverse events of benign prostatic hyperplasia (BPH) in the USA. BJU Int. 1998;109:84-91.

5. Taylor BC, Wilt TJ, Fink HA, Lambert LC, Marshall LM, Hoffman AR, et al. Prevalence, severity, and health correlates of lower urinary tract symptoms among older men: The MrOS study. Urol. 2006;68(4):804-809. Available from: https://dx.doi.org/10.1016/j.urology.2006.04.019. doi:10.1016/j.urology.2006.04.019.

6. Parsons JK, Mougey J, Lambert L, Wilt TJ, Fink HA, Garzotto $\mathrm{M}$, et al. Lower urinary tract symptoms increase the risk of falls in older men. BJU Int. 2009;104(1):63-68. Available from: https://dx.doi.org/10.1111/j.1464-410x.2008. 08317.x. doi:10.1111/j.1464-410x.2008.08317.x.

7. McVary KT, McKenna KE. The relationship between erectile dysfunction and lower urinary tract symptoms: Epidemiological, clinical, and basic science evidence. Current Urol Rep. 2004;5(4):251-257. Available from: https://dx.doi.org/10. 1007/s11934-004-0047-1. doi:10.1007/s11934-004-0047-1.

8. McVary KT, Monnig W, Camps JL, Young JM, Tseng LJ, van den Ende G. Sildenafil Citrate Improves Erectile Function and Urinary Symptoms in Men With Erectile Dysfunction and Lower Urinary Tract Symptoms Associated With Benign Prostatic Hyperplasia: A Randomized, Double-Blind Trial. J Urol. 2007;177(3):1071-1077. Available from: https://dx.doi.org/10. 1016/j.juro.2006.10.055. doi:10.1016/j.juro.2006.10.055.

9. Roehrborn CG, McVary KT, Elion-Mboussa A, Viktrup L. Tadalafil Administered Once Daily for Lower Urinary Tract Symptoms Secondary to Benign Prostatic Hyperplasia: A Dose Finding Study. J Urol. 2008;180(4):1228-1234. Available from: https://dx.doi.org/10.1016/j.juro.2008.06.079. doi:10.1016/j.juro.2008.06.079.

10. Pattanaik S, Sandhu HS, Mavuduru RS, Singh SK, Mandal AK. Efficacy of tamsulosin and tadalafil in relieving benign prostatic hyperplasia related symptoms: A randomized double blind placebo controlled cross-over study. Indian J Urol. 2019;35(1):25-25.

11. Stief CG, Porst H, Neuser D, Beneke M, Ulbrich E. A Randomised, Placebo-Controlled Study to Assess the Efficacy of Twice-Daily Vardenafil in the Treatment of Lower Urinary Tract Symptoms Secondary to Benign Prostatic Hyperplasia. Eur Urol. 2008;53(6):1236-1244. Available from: https://dx.doi.org/10.1016/j.eururo.2008.01.075. doi:10.1016/j.eururo.2008.01.075.

12. Madani AH, Afsharimoghaddam A, Roushani A, Farzan A, Asadollahzade A, Shakiba M. Evaluation of Tadalafil effect on lower urinary tract symptoms of benign prostatic hyperplasia in patients treated with standard medication. Int Braz J Urol. 2012;38(1):33-39. Available from: https://dx.doi. org/10.1590/s1677-55382012000100005. doi:10.1590/s167755382012000100005 .

Copyright: (C) the author(s), 2020. It is an open-access article distributed under the terms of the Creative Commons Attribution License (CC BY 4.0), which permits authors to retain ownership of the copyright for their content, and allow anyone to download, reuse, reprint, modify, distribute and/or copy the content as long as the original authors and source are cited.

How to cite this article: Prasad AN, Madhekar NKB. Tamsulosin and Tadalafil in Relieving Benign Prostatic Hyperplasia Related Symptoms- A Comparative Study. Acad. J Surg. 2020;3(1):8083.

DOI: dx.doi.org/10.47008/ajs/2020.3.1.17

Source of Support: Nil, Conflict of Interest: None declared. 